\title{
VERTICAL LATERAL LOAD RESISTING ELEMENTS FOR LOW TO MEDIUM RISE BUILDINGS INFORMATION FOR ARCHITECTS
}

\author{
A.W. Charleson ${ }^{1}$
}

\begin{abstract}
SUMMARY
This paper describes the development of a computer program for architects to provide guidance on wind and earthquake vertical lateral load resisting structure. The program, akin to an expert system, is suitable for designing low to medium-rise buildings in New Zealand at a preliminary design stage. Examples of design guides, providing more general lateral load resisting structural information for commonly used structural systems and materials, appropriate to a preliminary design stage, are also presented. Application of the program to the seismic design of a four storey reinforced concrete building is discussed.
\end{abstract}

\section{INTRODUCTION}

At the preliminary stages of a building design an architect requires approximate sizes of structural members in order to develop a conceptual design that can be described by drawings. If the architect has designed similar sized buildings and structural layouts in the past that experience may enable reasonably accurate estimates of vertical lateral load resisting structural element sizes to be made. Without prior experience, other sources of information are necessary, usually provided by structural engineers.

Early in the design process, the architect may feel it is premature to involve the services of an engineer, but is still interested in investigating the use of structure to provide order and form to the building. Various structural alternatives are required, so that the one best satisfying numerous architectural design criteria can be identified.

This is especially important for structure required to resist lateral loads which often has a far greater impact on architectural planning than gravity load resisting structure.

There is ample published information for establishing the size of gravity load resisting structural elements. In many texts for architects, structural sizes of, for example, beams and columns, are presented for wide ranges of systems, structural materials and spans $[1,7]$. Similar, less general information is available from trade literature and publications promoting a particular structural material. This is readily accessible to architects. However, there is no published information on lateral load resisting structure. Some texts $[7,8]$, describe the range of lateral load resisting systems and even how preliminary structural analyses can be undertaken, but information is lacking on the size of structural elements.

School of Architecture, Victoria University of Wellington (member).
During the preliminary design process, sooner rather than later, there should be input from all members of the design team. An experienced structural engineer can suggest additional, and perhaps more technically refined lateral load resisting alternatives (for example, arising from knowledge of the site), and advise at a more detailed level on the implications of each option. However, this interaction will be more fruitful if the architect already has some initial informed ideas and has an appreciation of approximate member sizes and configuration requirements. It is intended that the computer program RESIST, which is described in this paper, meets these needs.

\section{OVERVIEW OF RESIST}

RESIST is a computer program written specifically to provide architects with information on lateral load resisting structural requirements.

The approach taken during the program development has been to require as little input and knowledge of structural behaviour as possible from the user, compatible with obtaining sufficient accuracy, contributing to the necessary feature of program "user friendliness". The program is completely menu driven. Users can easily access over forty screens of context-sensitive information. The program may be used without the need of a manual or other reference material.

The primary output from RESIST is presented graphically (Figure 1). For a design to be acceptable the calculated performance of each structural action is to be less than or equal to $100 \%$. The designer can see if modification is required immediately.

Secondary information is also provided where there might be important architectural implications. Some examples are as follows; designers of reinforced concrete walls are given 


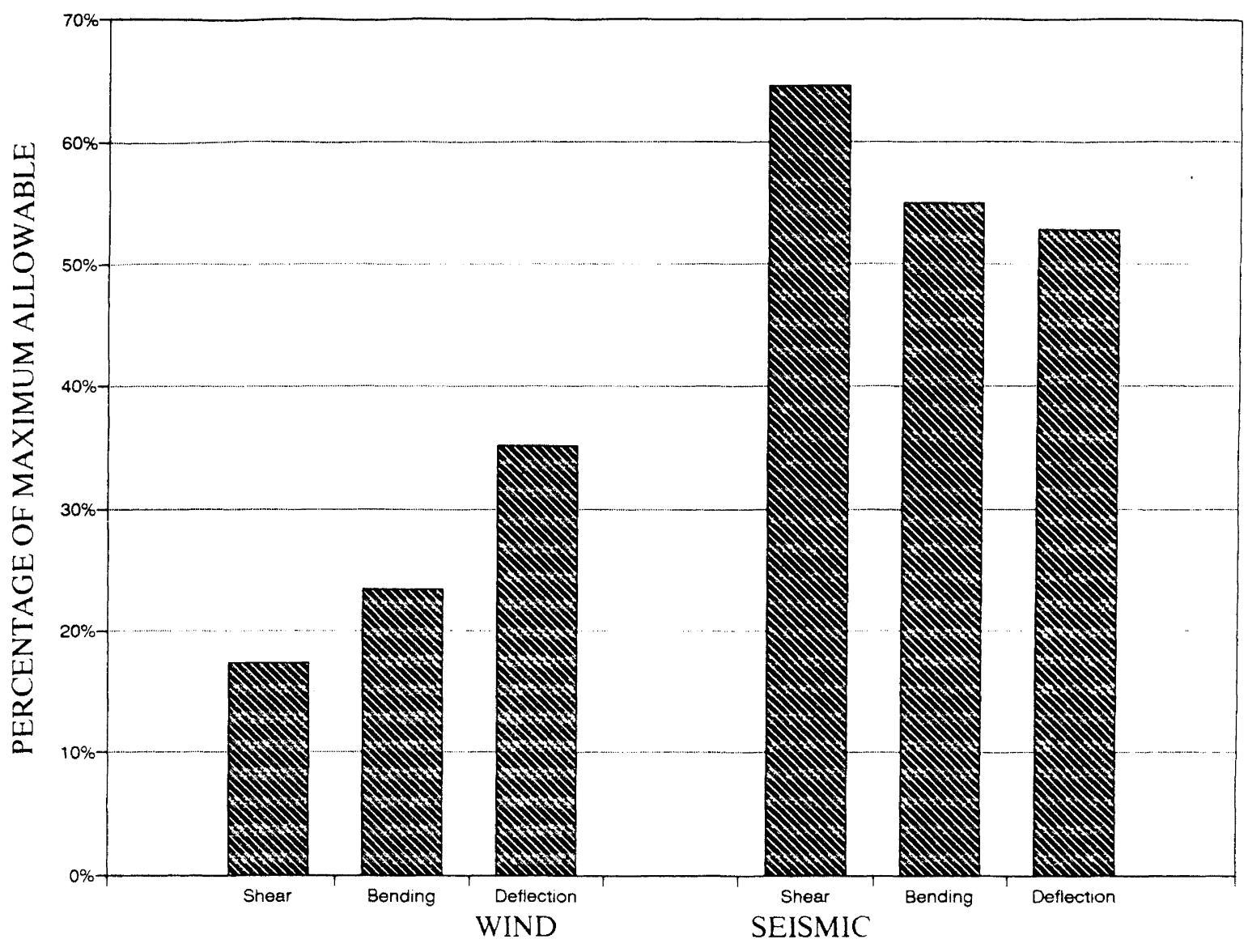

Figure 1

Example of principal output from RESIST

suggestions as to maximum penetration sizes and the possible need for thickening of wall returns to prevent compression chord buckling. Frame users are given the width of beam and column members which are related to their choice of frame member depth. After a bracing system has been analysed, chord dimensions are provided. For all structural configurations, information is presented on likely foundation requirements. If tension piles are needed to prevent overturning, the pile stem diameter is given. The architect can then appreciate the size of foundations to support the superstructure elements.

RESIST is not a direct design program. For the building under consideration the designer must first specify a structural material and then chose a structural configuration, including an estimate of member size. The program then evaluates and reports on the structural performance. The designer may then chose to change some parameters and iterate towards a structural system and configuration whose performance, when compared to New Zealand codes of practice and current structural engineering wisdom, is adequate. The final chosen structural system should, at the least be consistent with, and at best, considerably enhance the architectural design objectives.

RESIST is compatible with PC based computers. The program has been written in a spreadsheet format which has then been compiled to improve visual attractiveness and security.

\section{SCOPE AND LIMITATIONS OF RESIST}

\section{Building Size}

RESIST is limited to buildings up to and including eight storeys, and less than $30 \mathrm{~m}$ high. The design of higher buildings for wind and earthquake loads with sufficient accuracy would require increased input and computational effort reducing the program's acceptance. For example, the Loadings Standard [10] has both a simplified and a detailed design procedure for wind loads. RESIST uses the simplified approach allowed for buildings up to $15 \mathrm{~m}$ in height. However, this procedure yields sufficiently reliable results for buildings up to $30 \mathrm{~m}$ in height. The detailed approach can be used by a structural engineer if preliminary studies indicate that wind load is more severe than seismic load, and if a minimum structural solution is required.

Building height has been restricted also for the purpose of maintaining sufficient accuracy in the seismic design. Use of a simplified analysis may be too conservative for some buildings and unsafe for others due to possible detrimental effects of plan or vertical structural irregularities. A simple 
analytical approach is therefore suited to regular structures of modest height only. There is, however, no restriction on building size in plan.

\section{Simplicity of the structural system}

The program has the capacity to analyze one-way lateral load resisting structure only. Each building is therefore to be considered separately along each of its two major orthogonal axes. Further, only one type of structural system is permitted in each direction, and if several elements are used, they all must have the same material and dimensions. For example, if structural walls are proposed they all must have the same length, height and thickness. It is assumed member sizes remain constant up the building height. Where these requirements impose serious limitations on the design, structural engineering advice should be sought.

Consistent with recent structural engineering practice the lateral and gravity load resisting systems are considered separately. Nevertheless, gravity effects on some of the lateral load resisting structure are considered.

\section{Building Regularity in Elevation and Plan}

RESIST expects considerable building regularity. Inter-storey heights are assumed to be equal and all floors the same area and of the same building material. The plan configuration of vertical lateral load resisting elements is expected to be reasonably symmetrical. Modest torsional response is allowed for by a $20 \%$ shear increase per structural element where more than one resists lateral load in a given direction.

\section{Diaphragm Action}

Structural diaphragms are assumed to be effective at each floor level, distributing lateral forces into vertical elements. The presence of large penetrations in floor slabs could invalidate RESIST results.

\section{Foundation Conditions}

Foundation conditions are assumed to be "average". Soil type and profile affect structural performance significantly, so results from such simplified analyses must be used cautiously and be subject to appraisal by a structural engineer. If the soil is softer than that assumed, wind induced horizontal deflections and soft-soil seismic response amplification, may be underestimated.

\section{Structural Materials and Systems}

Designers have a realistic range of options with respect to choice of structural materials and systems. All combinations of material and systems commonly used in New Zealand may be designed using RESIST. Timber, structural steel, reinforced concrete masonry and reinforced concrete are available choices of materials. Lateral load resisting systems are structural walls (shear walls), moment resisting frames (excluding pitched portal frames) and braced frames. Bracing options comprise, compression/tension concentric, tension-only and eccentric bracing. It is anticipated that architects will go beyond the limited number of options available in RESIST when a given brief requires an uncommon or innovative structural system.

\section{DESCRIPTION OF STRUCTURAL ENGINEERING ASPECTS OF THE PROGRAM}

\section{Determination of Lateral Loads}

Primary sources used in the development of RESIST have been New Zealand codes of practice for design loads and structural materials [9 to 16$]$.

Simplified methòds for calculating wind and seismic loads have been used. For calculation of wind loads, the basic wind speed has been taken as the average speed from each of the seven New Zealand wind regions, using a single limit state multiplier. All buildings are assumed to be sited on the edge of the specified terrain. This means a terrain category with the next greater exposure is selected. The wind shielding multiplier has not been used due to the extensive site survey and analysis involved. Also, some minor simplification has been made to the Loading Standard's escarpment local topographical zone length to simply input requirements. The maximum allowable inter-storey deflection for the serviceability limit state has been taken as 0.002 and .007 times the height for suspended floors and roofs respectively.

For determination of seismic loads the equivalent static method is used in conjunction with basic seismic hazard acceleration coefficients for intermediate soil sites. There are some minor variances from the Loadings Standard that are discussed in the following section, however in all other respects designs comply with the Loadings Standard.

\section{Foundation Conditions}

Vertical foundation deformations are included in the assessment of horizontal deflections and assume elastic settlement of spread footings with acknowledged conservativeness [2] recognised by dividing theoretical values by 2.0 . Soil properties are assumed to be the average of a medium saturated clay and medium dense sand. A contact pressure of $300 \mathrm{kPa}$ for lateral load induced vertical load has been used to size footings and calculate deformations. Designers have the option of reducing settlement by up to a factor of 4.0 to allow for possible supplementary foundation beams, piling and other techniques to reduce settlement, and therefore lateral deflections.

Foundation deformation calculations are included for both wind and seismic loads. For slender ductile structural systems such as one bay eccentrically braced steel frames, foundation deformations may have a significantly adverse impact on deflection performance.

\section{Moment Resisting Frames: General}

The "portal" method of analysis [8], commonly used by structural engineers for preliminary design has been used. Points of inflection at mid-heights of columns and mid-spans of beams under lateral load are assumed. Other assumptions are that column bases are fixed against rotation, and columns and beams have the same dimensions. For steel frames the column depth (of a universal column section) is provided by the user, and universal beams with the same moment of inertia, are analysed.

For reinforced concrete and timber frames the designer inputs the column depth and RESIST calculates an 
appropriate thickness. For reinforced concrete and timber sections the width is assumed to be 60 and $70 \%$ of the depth respectively. A lower width to depth ratio for timber members was found to lead to column shear performance being frequently the limiting factor.

\section{Reinforced Concrete Frames}

For ultimate limit state seismic loads, the lower bound structural ductility factor of 6.0 for ductile frames has been chosen. Frames are designed to the provisions of NZS 3101 [15]. Where appropriate, advantage is taken of moment redistribution for ultimate limit state loads.

For wind and seismic loads, maximum achievable frame flexural strength is based on Grade 300 steel beam reinforcement ratios of $2.25 \%$ and $1.5 \%$ respectively. Maximum column strength is calculated assuming the code maximum allowable percentage of Grade 430 steel. The specified compression strength of concrete at 28 days is 30 MPa.

\section{Steel Frames}

Frames are designed to the provisions of NZS 3404 [13] and the HERA Design Guides [4].

The HERA recommendations acknowledge the inherent flexibility of steel moment resisting frames by suggesting that they are designed as structures of limited ductility $(\mu=3)$. This approach has been followed. Column design actions are obtained from nominally elastic response forces in the case of interior columns, or the lesser of elastic response or capacity beam actions for exterior columns.

Composite action between beams and concrete slab is assumed. Grade $350 \mathrm{MPa}$ structural steel is used for all members.

Shear performance of steel frames is not reported on as it can be modified as necessary by such techniques as increasing the web thickness that have minimal or no architectural implications.

\section{Timber Frames}

Timber frames are of Pinus Radiata No.1 Framing Grade glue-laminated construction. The relevant provisions of NZS 3603 [11] are applied in a working stress design approach with the Loading Standard ultimate limit state loads factored by 0.8 . Beam column connections utilizing epoxied reinforcing bars have been anticipated. A structural ductility factor $\mu=2$, recommended for frames with these joints [20] is used but timber member design is based on elastic response $(\mu=1)$, except for beams where the overstrength capacity of an assumed mild steel joint detail may be less.

\section{Reinforced Concrete Structural (Shear) Walls}

Design loads for each structural configuration of cantilevered walls are based on the maximum available ductility. This provides the designer with the opportunity of achieving minimum length walls. Ductility factors are as outlined in the previous loadings code [9] and later expressed in the new ductility format [16]. If the wall aspect ratio allows, full ductility up to $\mu=5$ is assumed, but for squatter walls a lower value, consistent with the wall aspect ratio is adopted.
Structural performance of a wall is evaluated for bending shear and deflection. Bending performance is expressed as a percentage of the ultimate limit state design moments compared to the maximum dependable flexural capacity. This latter value assumes $75 \%$ of the maximum code allowable reinforcement ratio is placed uniformly along the wall length. This is a simplification of current design practice where flexural reinforcement is concentrated at each wall end. Grade 430 reinforcing steel and $25 \mathrm{MPa}$ concrete strength is assumed. Shear performance expresses the maximum overstrength capacity shear stress as a percentage of the maximum code allowable concrete shear stress. A similar approach applies to deflection performance. Allowance is made for concrete cracking and reinforcing pullout at foundation level [5]. Whereas bending and shear performances are governed by wall base actions, deflection performance is assessed on the maximum inter-storey deflection occurring in any storey.

\section{Reinforced Concrete Masonry Structural Walls}

Design is in accordance with the masonry design code [14]. The same approach to evaluating structural performance as used for reinforced concrete applies with the following modifications. The dependable bending strength of walls is based on one D20 reinforcing bar per block flue which represents the maximum area of steel allowed, taking bar lapping into account. For the calculation of shear performance, Grade A masonry, and masonry compressive strength equal to or greater than $12 \mathrm{MPa}$ is assumed. This allows for the adoption of the maximum grade-dependent shear stress values of $2.4 \mathrm{MPa}$ or $1.8 \mathrm{MPa}$, depending on the ductility demand.

Shear performance is calculated using the lesser of the ultimate limit state design shear (with a flexural overstrength factor of 2.0) or elastic response $(\mu=1.25)$.

\section{Timber Structural Walls}

The two material design codes used are the timber design and the construction plywood codes $[12,11]$.

All walls are assumed to be fully ductile with wall sheathing and chords designed for elastic response. This approach is somewhat conservative when compared to that of Thomas [19], but it does overcome the uncertainty in calculating the wall overstrength factor due to strength enhancement from the likely use of gib internal lining [17].

Shear performance is based on design shears from 0.8 times ultimate limit state wind and seismic loads. In the absence of a timber limit state code, working stress design has been used. Shear strength is taken as the maximum of the shear strength provided by double sided $21 \mathrm{~mm}$ ply clad walls, or two rows of $2.89 \mathrm{~mm}$ gun nails, as suggested by Stewart and Dean [18], spaced at $30 \mathrm{~mm}$ centres on each side of the framing. This represents the practical upper bound achievable nailed strength of a ply clad wall.

Wall chord members are constructed from sawn and dry No. 1 Framing Grade Pinus Radiata. Chords, resisting gravity and overturning compression and tension forces, have their performance evaluated on the number of ex $50 \mathrm{~mm}$ thick members required to be nailed together to construct a chord, compared to the maximum practical number, considered to be 10. The depth of chord members is related to inter-storey height and magnitude of chord compression load. 
Deflections from shear, bending and foundation deformations are calculated. Nail slip, as determined by Thomas has been allowed for. Base rotation of the wall is calculated assuming a constant compression chord axial deformation of $3 \mathrm{~mm}$ and the tensile extension of a steel rod, sized for strength, anchored at foundation level and connected to the timber chord at first floor level.

\section{Steel Braced Frames}

Designers may choose from several types of braced frames; tension-only bracing, compression and tension cross bracing, concentric $\mathrm{K}$ bracing, or eccentrically $\mathrm{K}$ braced frames. The design rules from the steel design code [13] have been followed except that maximum height limitations of some bracing configurations and some other provisions are from a draft version (October 1991) of Section 12.12 of NZS 3404:1992.

For seismic loads, eccentrically braced frames are assigned a ductility factor $\mu=6$. For tension-only bracing, $\mu$ varies from 1.25 to 6 depending on the number of storeys, but for other types of bracing $\mu=1.25$ is used. Although this approach may be conservative, designs will be controlied by loads rather than code rules which are not able to develop such a good feel of structural behaviour.

Grade 350 steel is used for all members except for tensiononly bracing where Grade 250 is assumed.

For braced frames RESIST calculates the size of the chords (edge columns) to the braced bays assuming either a tube or universal column cross-section. The designer is informed of both options.

As mentioned above, eccentrically braced frames are assumed to be fully ductile for ultimate limit state seismic loads. The inclined struts and edge columns are designed for twice code load to allow for the fuse overstrength factor. Lateral deflections are calculated by first assuming concentric bracing, and then applying a modification factor as recommended by Popov and others [6].

\section{Timber Braced Frames}

For large timber column and bracing members (depths greater than $200 \mathrm{~mm}$ and $300 \mathrm{~mm}$ respectively), No. 1 Framing Grade glue-laminated timber is assumed. Ultimate limit state timber stresses have been obtained from the draft timber code [21]. Elastic response $(\mu=1)$ is the basis for seismic design.

As for steel bracing, designers are informed of required chord sizes which are also used for deflection calculations. Bolting requirements for the critical brace are presented.

\section{INFORMATION ON LATERAL LOAD RESISTANCE}

Although the principal intended use of the program is to enable designers to consider many lateral load resisting options for each building being designed, RESIST has been used to generate general information about lateral load resisting requirements. In Figures 2 to 5 selected information from some of the more common combinations of structural materials and lateral load resisting systems is presented for seismic loads. Similar graphs have been constructed [3] to investigate wind loads and alternative structural configurations such as for various numbers of walls or frames in a building.

Brief descriptions of building construction information are shown in each figure but some elaboration is required. Heavy, medium and light floor construction relates to precast concrete construction with cast-in-place concrete, steel frame and cast-in-place concrete on steel decking, and timber construction respectively. Wall cladding and partitions are classified as heavy if precast panels and concrete masonry blockwork is present, and light if the construction is lined timber framing. Medium roof weight is applicable to concrete tiles on timber rafters while a light roof would consist of corrugated iron or equivalent cladding. The building classification in each case is that for an office building. Finally, the term "ordinary foundations" describes what has been outlined previously, whereas "very extensive" describes the construction of foundation beams, or other methods, to reduce vertical settlement and hence lateral drift.

\section{EXAMPLE APPLICATION}

In this example, RESIST is used to design vertical seismic load resisting structure in one orthogonal direction for a four storey building situated in Wellington. The suspended floors of the building are heavy, with a medium weight roof and lightweight cladding and interior partitions. The interstorey heights are $3.5 \mathrm{~m}$ with a $1.0 \mathrm{~m}$ high roof. The building is square, with a plan dimension of $33.3 \mathrm{~m}$. Ordinary foundations are assumed. Various structural configurations utilising reinforced concrete walls, reinforced concrete masonry walls, and reinforced concrete moment resisting frames have been investigated. In Figure 6 a selection of ground floor structural footprints are presented. Two points are of particular interest. First, a reduction in footprint area as fewer structural elements are used is clearly illustrated. Secondly, the shape of a footprint will change considerably if infinitely rigid foundations are assumed. In this case, two walls $3.5 \mathrm{~m}$ long by $700 \mathrm{~mm}$ wide meet Code requirements.

Using structural options such as these, and preferably more, the architect can determine relatively easily which configuration will best suit the overall design objectives, including functional and aesthetic considerations.

\section{CONCLUSIONS}

This paper describes the development of a computer program, which has enabled the production of design guides to be used to assist with the preliminary design of vertical lateral load resisting elements. However, more importantly, the program will provide architects with design information on the requirements of vertical lateral load resisting systems for a particular building very quickly. This should enable a far greater degree of exploration of potential seismic and wind resisting structural systems, enhancing not only the buildings's architectural quality due to better integration of structure with planning and other design considerations, but also the seismic performance. 


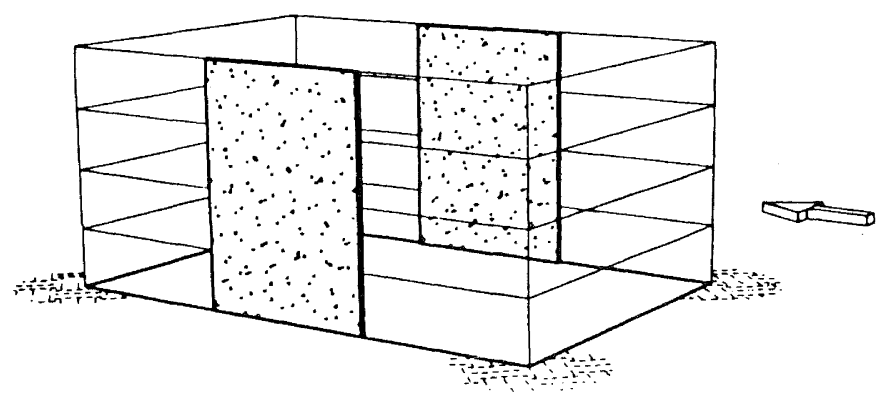

BUILDING DATA

Floor Construction : Heavy

Wall Cladding : Heavy

Partitions : Heavy

Roof Construction : Medium

Interstorey Height : $3.5 \mathrm{~m}$

Occupancy Class : Office

Classification : 4

Foundations : Ordinary

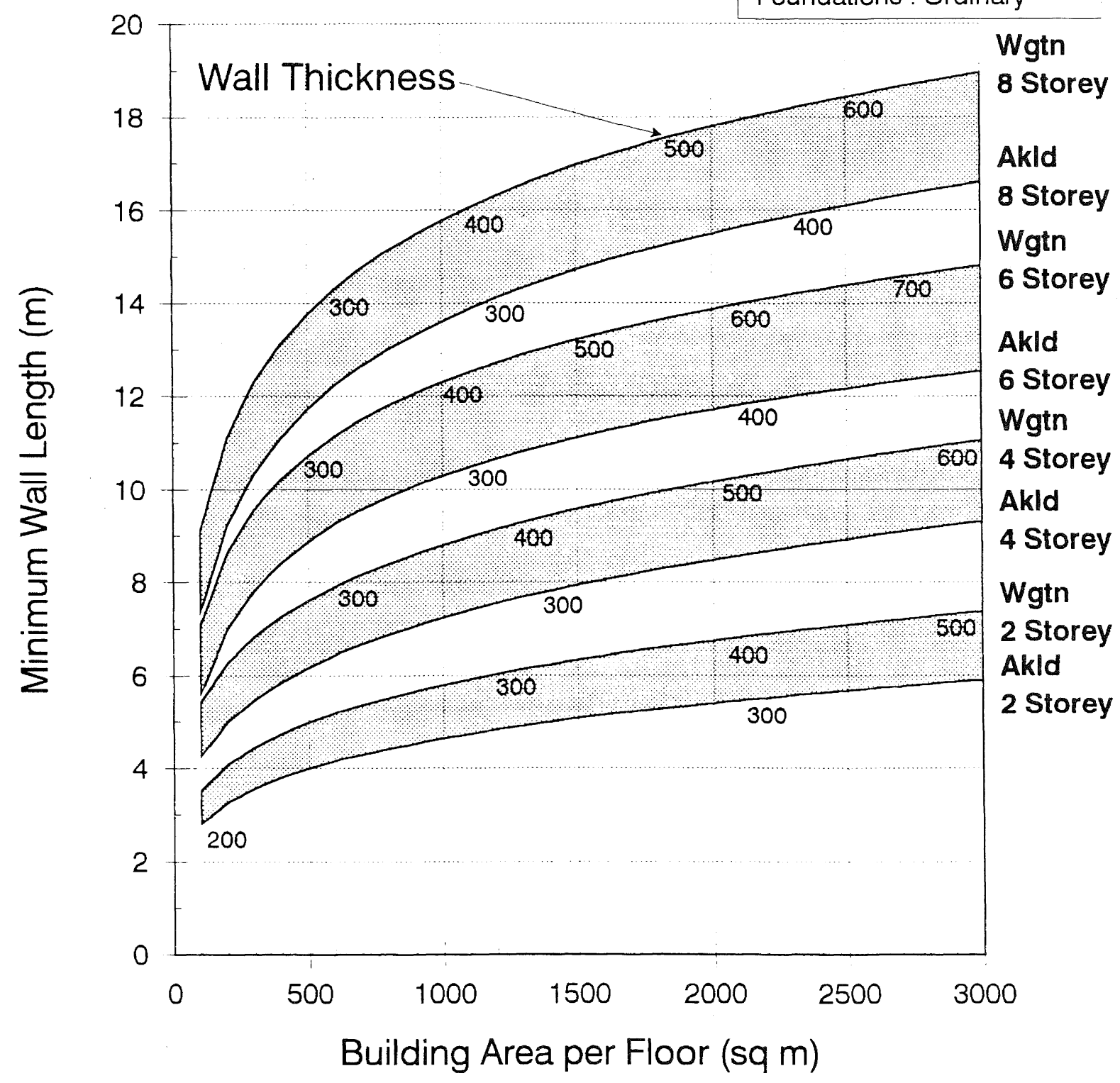

Figure 2

Reinforced concrete structural walls. Minimum wall lengths required for various numbers of storeys with two walls: seismic loads 


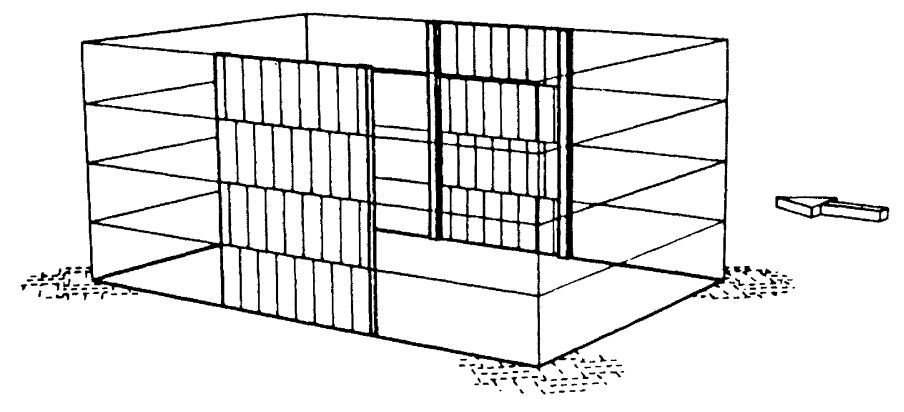

BUILDING DATA

Floor Construction : Light Wall Cladding : Light

Partitions : Light

Roof Construction : Light Interstorey Height : $3.5 \mathrm{~m}$ Occupancy Class : Office Classification : 4

Foundations : Ordinary

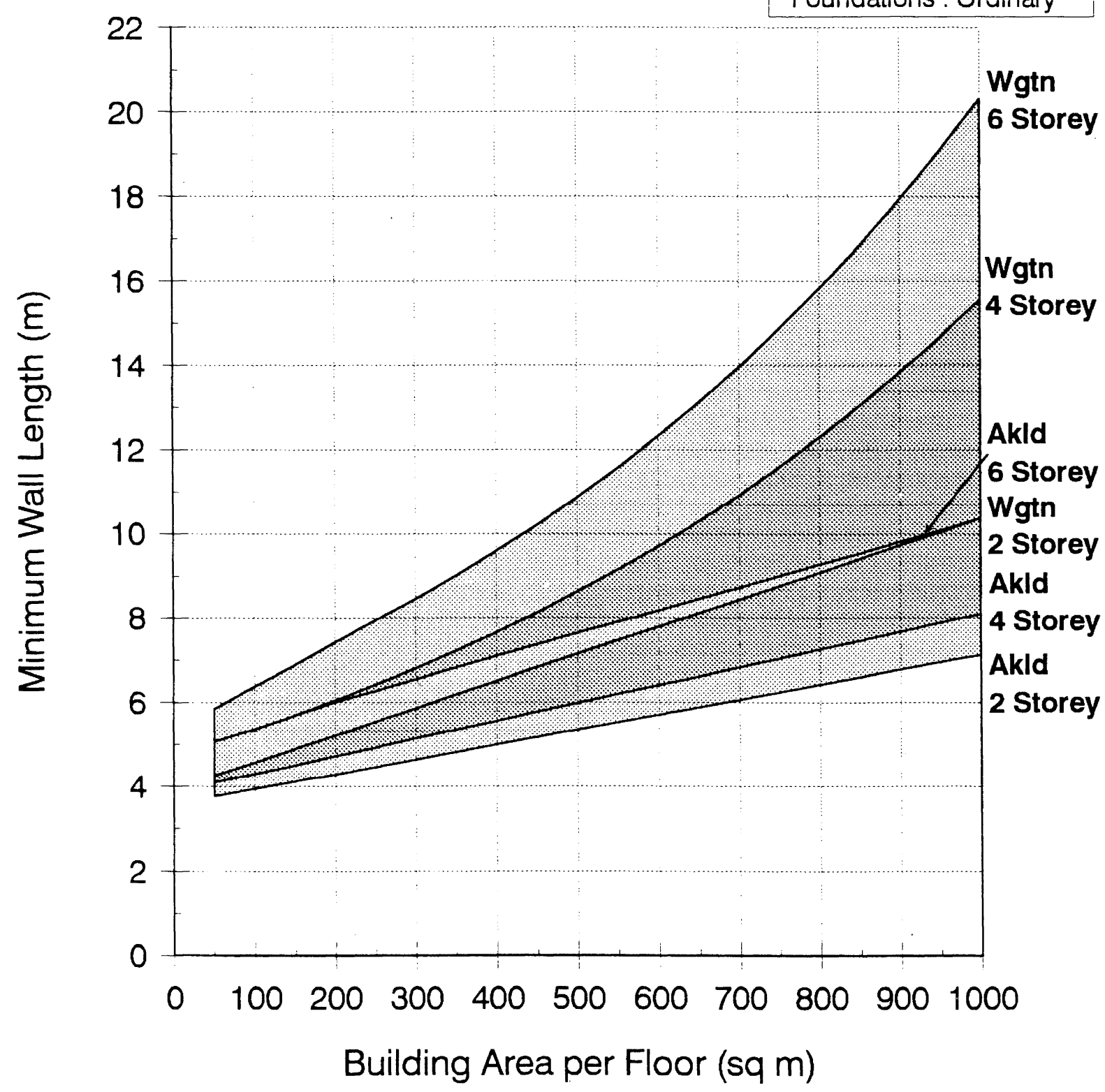

Figure 3 


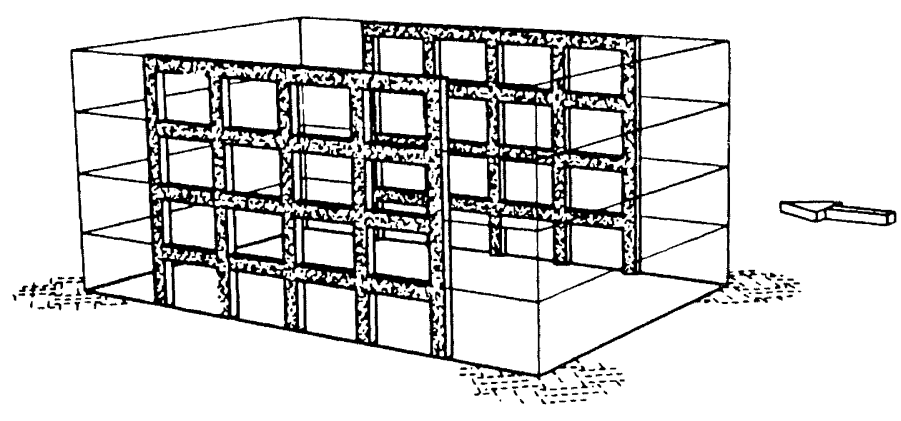

\section{BUILDING DATA}

Floor Construction : Heavy

Wall Cladding : Heavy

Partitions: Heavy

Roof Construction : Medium

Interstorey Height : $3.5 \mathrm{~m}$

Occupancy Class : Office

Classification : 4

Foundations: Ordinary

Figure 4

Reinforced concrete frames. Minimum column depths required for various numbers of storeys with two frames, each of four bays: seismic loads. 


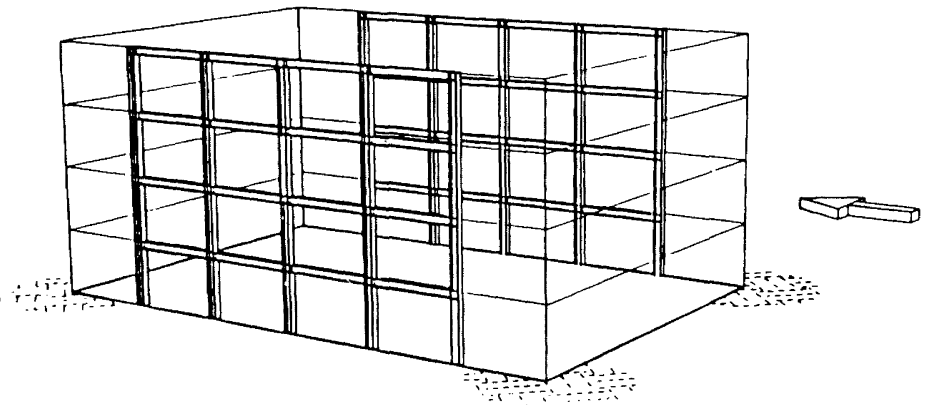

BUILDING DATA

Floor Construction : Medium

Wall Cladding : Medium

Partitions : Medium

Roof Construction : Medium Interstorey Height : $3.5 \mathrm{~m}$ Occupancy Class : Office Classification : 4 Foundations : Ordinary

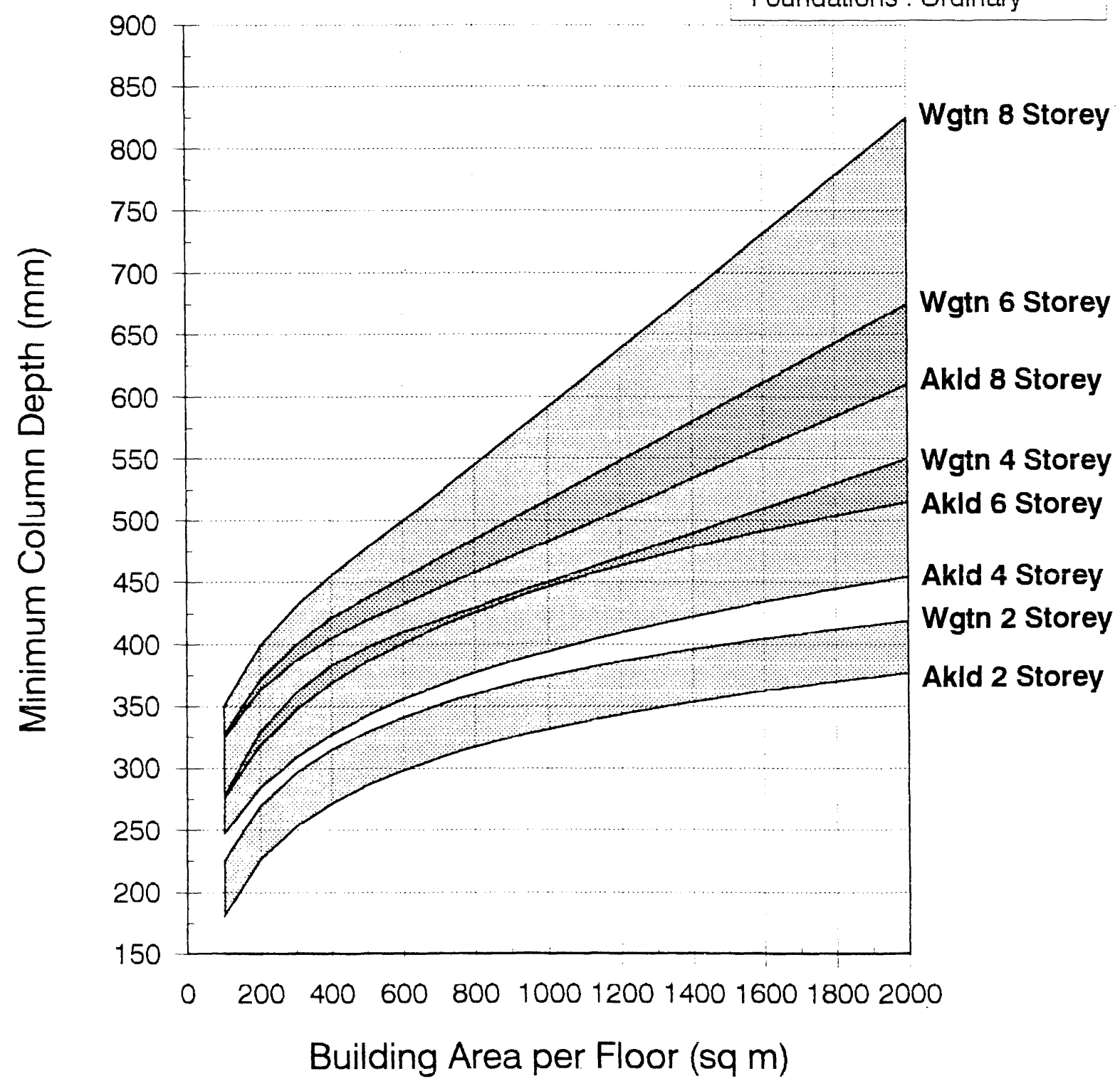



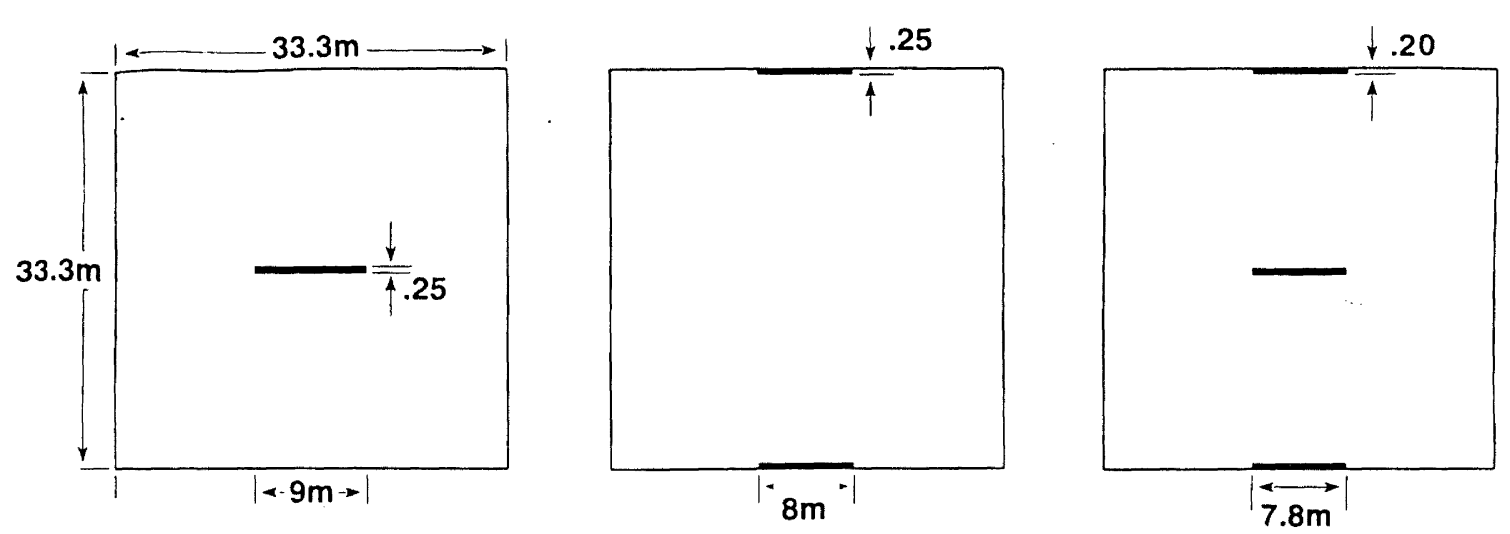

Reinforced concrete walls
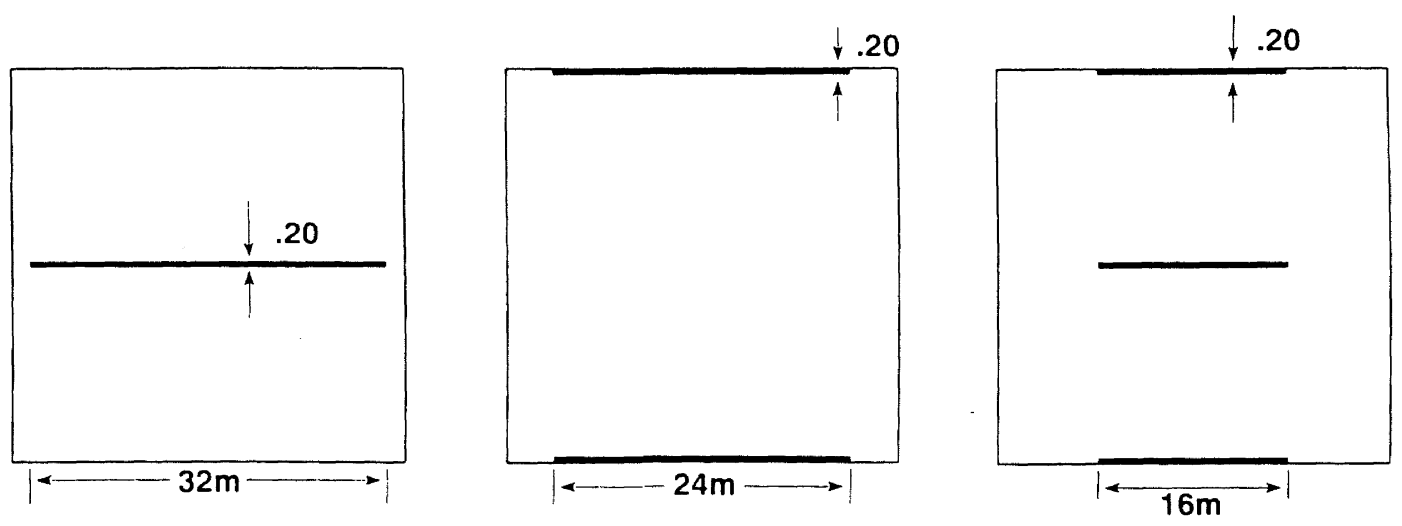

Reinforced concrete masonry walls
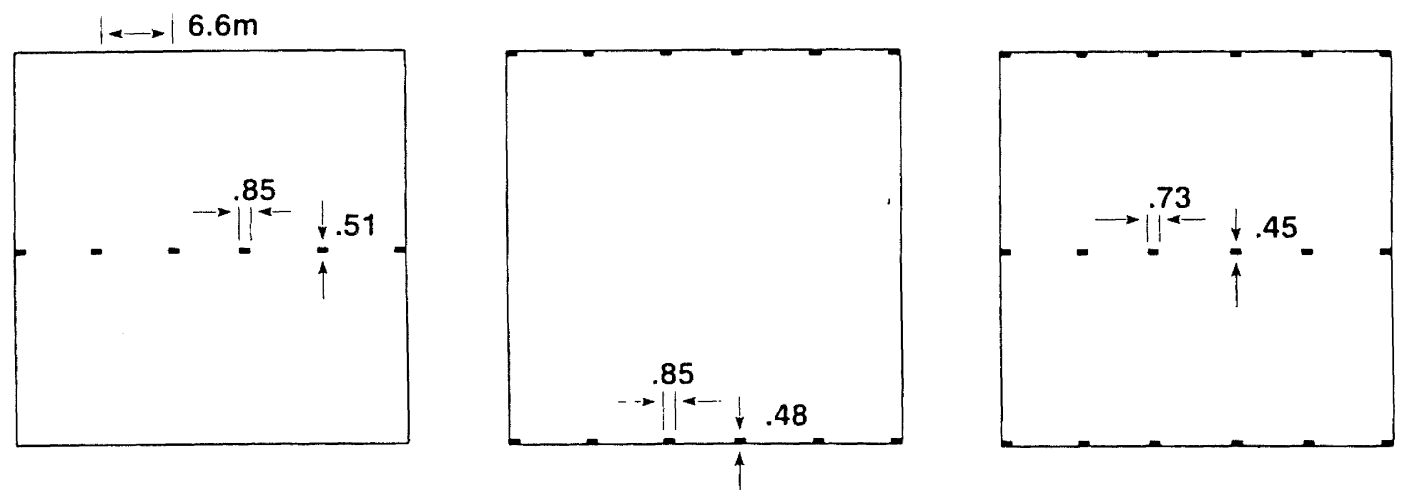

Reinforced concrete frames, 5 bays per frame
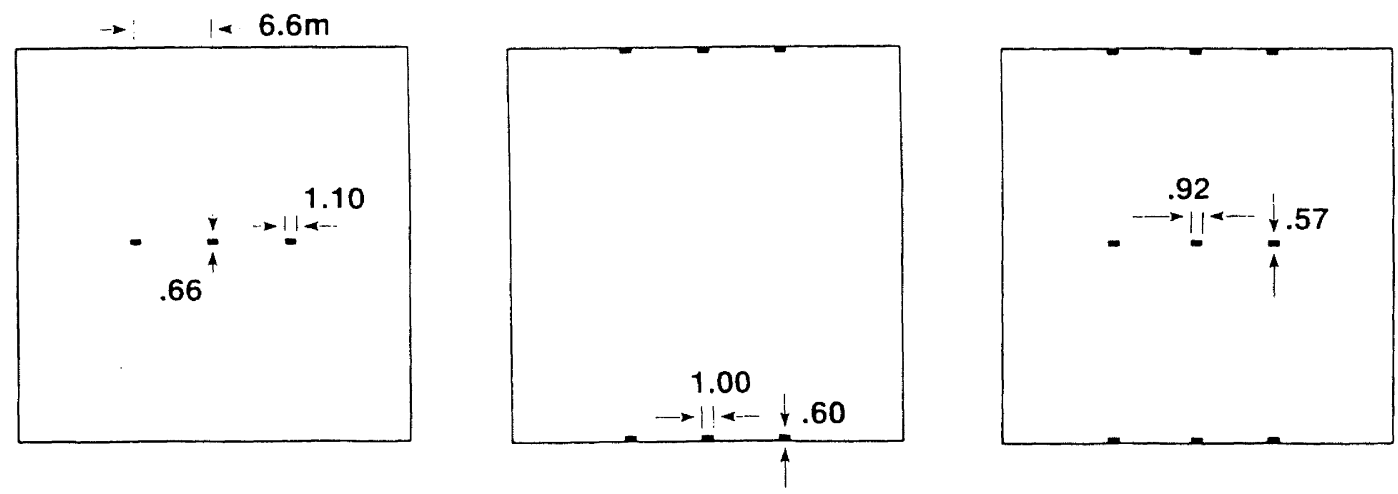

Reinforced concrete frames, 2 bays per frame

Figure 6

Ground floor level structural footprints for seismic load resistance in one direction for various numbers of structural elements. (Additional gravity load resisting structure not shown.) 


\section{ACKNOWLEDGEMENTS}

The financial support of the New Zealand Earthquake and War Damage Commission is gratefully acknowledged.

The constructive comments of structural engineering and architectural colleagues have been greatly appreciated, as have comments from several classes of architectural students who have used RESIST at various stages of development.

Andrew Vere-Jones for his work in enhancing the user friendliness of the program and plotting the graphs.

\section{REFERENCES}

1. Benjamin B.S. 1984. Structures for Architects. 2nd Ed. Van Nostrand Reinhold, New York.

2. Bowles J. E. 1977. Foundation Analysis and Design. Second Edition. McGraw-Hill Kogakusha Tokyo.

3. Charleson A. W. 1993. Wind and Earthquake Load Resisting Structure for Buildings - design guides for architects. Centre for Building Performance Research, Victoria University of Wellington.

4. HERA. 1990. New Zealand Structural Steelwork Design Guides Volume 2, (incorporating amendment no 3, September 1990). Heavy Engineering Research Association of New Zealand. Auckland.

5. Paulay T. and Williams R. L. 1980. The Analysis and Design of and the Evaluation of Design Actions for Reinforced Concrete Ductile Shear Wall Structures. Bulletin of the New Zealand National Society for Earthquake Engineering, Vol.13 No.2:108-143.

6. Popov E. P., Kasai K. and Engelhardt M. D. 1986. Advances in Design of Eccentrically Braced Frames. Proceedings of the Pacific Steel Conference, Auckland. Vol.1: 85-95.

7. Schodek D. L. 1980. Structures. Prentice-Hall Inc., New Jersey.

8. Schueller W. 1990. The Vertical Building Structure. Van Nostrand Reinhold, New York.

9. Standards Association of New Zealand. 1984. Code of Practice for General Structural Design and Design Loadings for Buildings. NZS 4203. Wellington.
10. Standards Association of New Zealand. 1992. Code of Practice for General Structural Design and Design Loadings for Buildings. (SANZ Loading Standard) NZS 4203. Wellington.

11. Standards Association of New Zealand. 1981 Specification for Strength Properties and Design Methods for Construction Plywood. NZS 3615. Wellington.

12. Standards Association of New Zealand. 1990. Code of Practice for Timber Design. NZS 3603 Wellington.

13. Standards Association of New Zealand. 1989. Steel Structures Code: Parts 1 and 2. NZS 3404. Wellington.

14. Standards Association of New Zealand. 1990. Code of Practice for the Design of Masonry Structures. NZS 4230. Wellington.

15. Standards Association of New Zealand. 1982. Code of Practice for the Design of Concrete Structures: Parts 1 and 2. NZS 3101. Wellington.

16. Standards Association of New Zealand. 1989 General Structural Design and Design Loadings for Buildings. 2/DZ 4203. Wellington.

17. Stevenson R. B. and Beattie G. J. 1989. Investigation of the Influence of Architectural Cladding on Structural Timber Walls. Central Laboratories Report 89-B5208, Works Consultancy Services, Wellington.

18. Stewart W. G. and Dean J. A. 1989. A Procedure for the Seismic Design of Timber Sheathed Shearwalls. Proceedings of the Second Pacific Timber Engineering Conference, Auckland. Vol.2 pp. 273-281.

19. Thomas G. C. 1991. The Feasibility of Multistorey Light Timber Frame Buildings. Research Report 912, Department of Civil Engineering, University of Canterbury, Christchurch.

20. Timber Structures Research Group. 1992. Multistorey Timber Buildings. Newsletter No. 5, October 1992. University of Canterbury, Christchurch.

21. Walford G.B. 1990. Draft Revision of Code of Practice for Timber Design : Limit States Version. Forest Research Institute, Rotorua. 